\title{
Deep Level Defects in He-implanted n-6H-SiC Studied by Deep Level Transient Spectroscopy
}

\author{
X. D. Chen, C. C. Ling, S. Fung, C. D. Beling, and H. S. Wu
}

Deparment of Physics, The University of Hong Kong, Pokfulan Road, Hong Kong, P R China

G Brauer, W. Anwand, and W. Skorupa

Institut fir lonenstrahlphysik und Matenalforschung, Forschungstentrum Rossendon, Posffach 510119. D-01314 Dresden, Gemany

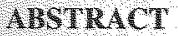

Deep level transient spectroseopy (DLTS) was used to study deep level defects in He-implanted n-type $6 \mathrm{H}-\mathrm{SiC}$ samples. Low dose He-implantation (fuence $-2 \times 10^{\text {I }}$ ions $\left(\mathrm{cm}^{2}\right)$ has been employed to keep the as-implanted sample conductive so that studying the introduction and the thermal evolution of the defects becomes feasible. $A$ strong broad DIrS peak at $275 \mathrm{~K}-375 \mathrm{~K}$ (called signal B) and another deep level at $E_{c} 0.50 \mathrm{eV}$ were observed in the as-implanted sample. The intensily of the peak B was observed to linearly proportional to the logarithm of the filling pulse width, which is a signature for electron capture into a defect related to dislocation. Affer annealing at $500^{\circ} \mathrm{C}$, the intensity of peak was significantly reduced and the remained signal has properties identical to the well known $Z / Z$, deep defects, although it is uncertain whether the $Z / Z_{2}$ exist in the as mplanted sample or it is the annealing product of the dislocation-related defect. The $E_{1} / E_{2}$ defect (It) $0.370 .4 \mathrm{eV}$ ) was not presence in the as-implanted sample, but was observed after the $300^{\circ} \mathrm{C}$ annealing.

\section{INTRODUCTION}

Silicon carbide $(\mathrm{SiC}$ ) is a wide band-gap semiconductor material having unique physical and electronic properties for fabricating high-temperature, high-power, and high-frequency clectronic devices [1]. Lon-implantation is an important techique for the selective doping of $\mathrm{SiC}$ beeause of the extremely small diffusion constants of the dopant impurities in SiC: Defects are usually induced by the ion implantation or the post-implantation annealing processes and some of these defects do not anneal out at very high temperatures [2-4]. Ion implantation or particle irradiation induced deep level defects in SiC have been extensively studied by capacitance transient techniques such as deep level transient spectroscopy (DLTS) [2 11. Deep levels at Ec-0.60.70V (termed $\left.Z_{1} / Z_{2}\right)$ are generated either by electron iradiation or by ion implantation, and the concentration of these centers is reduced by annealing below $1000^{\circ} \mathrm{C}$ Another pair of important deep levels Ec $0.310 .4 \mathrm{eV}$ are usually referred to $\mathrm{E}_{1} / \mathrm{E}_{2}$ and the concentration of these centers is strongly reduced (the DUTS signal of $\mathrm{E}_{1} / \mathrm{E}_{2}$ is below the detection limit) by annealing at $1200-1400^{\circ} \mathrm{C}[2-11] \mathrm{E} / \mathrm{E}_{2}$ are the dominani peaks in the DLTS spectra of the as-electron-iradiated 6H-SiC samples [4-8]. For the cases of deuterium implanted $[4]$, He implanted $[3,6,9]$, and neutron irradiated $[10]$ n-type $6 \mathrm{H}-\mathrm{SiC}, \mathrm{E}_{1} / \mathrm{E}_{2}$ are not the peaks having the highest intensities. However their intensities increase with increasing annealing temperature before they stat annealing out $[3.4,10]$. The less prominent peaks labeled $\mathrm{E}_{i}$ at $\mathrm{E}_{\mathrm{C}}-0.50 \mathrm{eV}$ is usually observed in electron 
irtaduted n-type $6 \mathrm{H}-\mathrm{SiC}$ materials and they anteal out at a relatively low temperature of $-300^{\circ} \mathrm{C}$ Y7. RD5 is another defed observed in He-implanted 6H-SiC and it has an ionization energy of $0.43-0.47 \mathrm{eV}$.

In this work, n-type $6 \mathrm{H}-\mathrm{SiC}$ samples were mplanted with He ion with a relatively

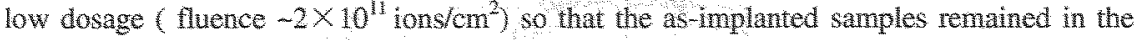
conductively range suitable for DLTS measurement. DLTS technique was then employed to study the formation and the thermal evolution of the deep level defects induced by the He implantation process

\section{EXPURMENTAL DETAIIS}

The starting n-type $6 \mathrm{H}$-SiC material used in the present study was 5 -4m-thick nitrogen doped $(0001)$ oriented epitaxial layer $\left(1 \times 10^{16} \mathrm{~cm}^{-3}\right)$ grown on $\mathrm{n}^{+}$type $6 \mathrm{H}-\mathrm{SiC}$ substrate $\left(8 \times 10^{17} \mathrm{~cm}^{-3}\right)$ purchased from Cree Research Inc. The samples were rinsed in boiling acetone, ethanol, and de-ionized water, and were then chemically treated in $10 \%$ hydrofluoric acid solution to remove the oxidation layer. Large area Ohmic contacts were made by evaporating Al on the substrate backside of the samples followed by a 5 min annealing process at $900^{\circ} \mathrm{C}$ in pure nitrogen gas.

The sanples were implanted with He jons at energies of $55 \mathrm{keV}, 210 \mathrm{keV}, 430 \mathrm{keV}$, $665 \mathrm{keV}$ and $840 \mathrm{keV}$ (each with fluence of $-2 \times 10^{11}$ ions $/ \mathrm{cm}^{2}$ ) so as to produce a $2 \mathrm{um}$ deep box-shape implanted layer Schottky contacts for DLTS measurenent were prepared by thermally evaporating gold dots of $0.6 \mathrm{~mm}$ diameter on the implanted surface of the epitaxial layer. The quality of all the Schotky-diode-like samples was monitord by observing the current-voltage (I-V) and the capacitance-voltage (C-V) characteristics. Each of the isochronal thermal annealing steps was carried out in the argon atmosphere for $30 \mathrm{~min}$.

DLTS spectra were taken in the temperature range of $100-400 \mathrm{~K}$. The lonization energies and the capure cross sections of the deep level defects were determined from the Arrhenius plots. The trap concentrations were evaluated from the peak heights of the DLTS signal. In the calculations, the defect capture cross sections were assumed to be temperature independent.

\section{RESULTS AND DISCUSSION}

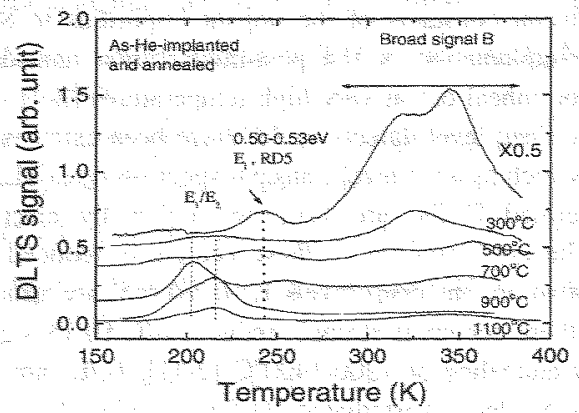

Figure 1. DLTS spectra for He-implanted n-type $6 \mathrm{H}-\mathrm{SiC}$ with subsequent annealing at $300^{\circ} \mathrm{C}$, $500^{\circ} \mathrm{C}, 700^{\circ} \mathrm{C}, 900^{\circ} \mathrm{C}$, and $1100^{\circ} \mathrm{C}$, respectively. 
Figure 1 shows the DUTS specta of the He-implanted samples subjected to differen annealing conditions. DLTS measurements were also performed on the as-grown control sample and no deep level signal was observed (detecton limit $-10^{13} \mathrm{~cm}^{3}$ ). This indicates that al the observed defect levels are induced by the He implantation. For the as-He-implanted sample, peak at $-240 \mathrm{~K}$ and a broad signal (denoted by B) wete clearly observed. From the Arrhenius plots in figure 2 , the activation energies of the $240 \mathrm{~K}$ peak and the broad peak B was Ec-0 50eV and EC $0.89 \mathrm{eV}$ respectively.

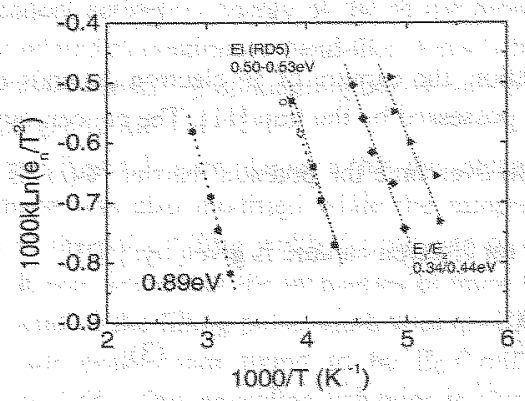

Figure 2. Arthenius plots of the emission rates $1000 \mathrm{kLn}\left(\mathrm{e}_{\mathrm{n}} \mathrm{T}^{2}\right.$ ) v recprocal temperature for the observed deep level defects, respectively,

In order to investigate the nature of the broad signal in the as-implanted cample, DLTS spectra with different flling pulse width and different reverse bias voltage were taken and they were shown in figure 3 .

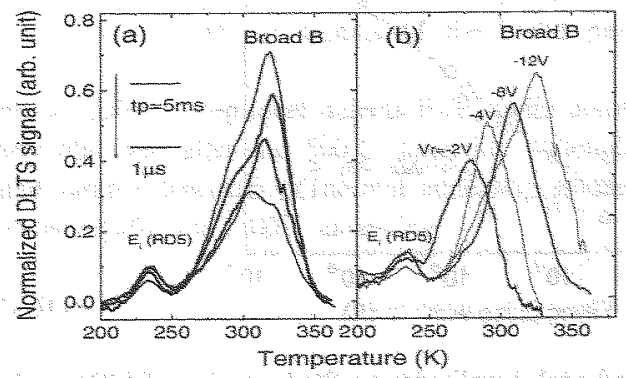

Frgure 3. DLTS spectra obtained under (a) different filing pulse duration time tp; and (b) reverse bias Vi for the as-He-implanted n-type 6H-SiC.

For the spectra with different hiling pulse width tp, it can be clearly seen that the broad peak B consists of more than one peak and these peaks' intensities have different filing pulse widh dependence. Interestingly, the intensities of the observed dominant peak (he broad peak B) increase even with filing pulse widths longer than $10 \mathrm{~ms}$ (as shown in Fig.3(a) and the peak temperature position are found to shif to higher temperature using the same rate window with varying of measurement revise bias (as shown in Fig 3 (b)). 
For ideal point defects, electron capture of the trap is described by the rate equation;

$$
\frac{d N_{f}}{d t}=-n v \sigma_{n}\left(N_{t w}-N_{f}\right)
$$

$\mathrm{N}_{\mathrm{r}}$ is the fllled electron trap density, $\mathrm{N}_{\text {totat }}$ is the total trap density $n$ is the free electron density. $v$ is the free electron thermal velocity and $\sigma_{n}$ is the capture cross section of the trap. This implies after the filling pulse period of $\mathrm{t}_{\mathrm{p}}$, the filled electron trap density would be equal to:

$$
N_{i}\left(i_{p}\right)=N_{T}\left(1-\exp \left[-n v \sigma_{n} t_{p}\right]\right)
$$

However, for a defect related to the dislocation, the capture of an electron depends on the potential barricr and this the charge already possessed by the trap [11]. The concentration of the free electrons that have enough energy to overcome the potential barrier $\Phi(t)$ is given by: nexp $(-q \Phi(t) / k T)$. The rate equation for electron capture is given by: [12]

$$
\frac{d N_{f}}{d t}=\sigma_{n} m N_{T}[1-f(t)] \exp \frac{-q \Phi(t)}{k T}
$$

$f(t)$ is the fraction of traps being flled and thus $N_{f} \in f N_{T}$. The time evolution of electron capture of the dislocation is given by: [12]

$$
N_{f}\left(t_{p}\right)=\sigma_{n} w n N_{T} \mathrm{n}\left[\left(t_{p}+t\right) / \tau\right)
$$

where $t$ is a constant.

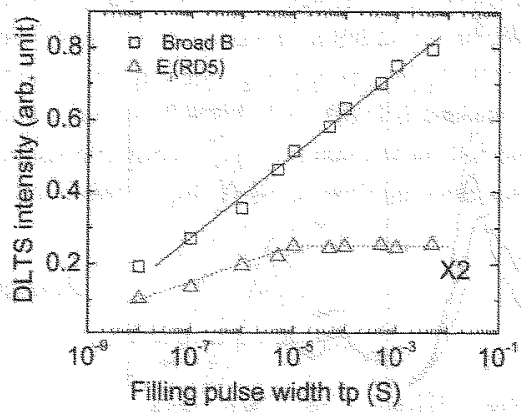

Figure 4 Dependence of the observed peak amplitudes on the logarithm of filling pulse time tp ranging from 0.1 us to $10 \mathrm{~ms}$ in the as-He-implanted sample.

Figure 4 shows the DLTS intensities of the broad signal B and the $0.50 \mathrm{eV}$ peak as a function of $i_{p}$. The data of the broad peak $B$ follow a linear relationship for over four orders of magnitude of $\mathrm{p}$ and the increase of the intensity of the signal $\mathrm{B}$ with $\log \left(\mathrm{t}_{\mathrm{n}}\right)$ over a wide range from $10^{-8}$ to $10^{-2} \mathrm{~s}$, moreover, the peak intensity of peak $\mathrm{B}$ increases with increasing. flling pulse width even for flling pulse width as large as loms indicating that the broad peak $B$ is indeed related to defects due to dislocation-like -or point-defect cluster with dangling. bonds, where charge bullup potential barrier govems the capture rate (refer to equation (4)). 
The saturation of the $0.50 \mathrm{eV}$ peak intensity at arge $\mathrm{f}$ is the typical behavior for point defect. as from equation (2) $\mathrm{N}_{f}\left(t_{\mathrm{p}}\right)$ saturates as $\mathrm{t} p>\left(\mathrm{nvo}_{\mathrm{p}}\right)^{-1}$. On the oher hand, DLTS measurements under different reverse bias show the bias dependence of the deep level activation energies (as shown in figure $3(\mathrm{~b})$. The Armenius plot in figure 2 shows that the activation energies of signal $B$ is $E_{c}-0.89 \mathrm{cV}$. It was found that with reverse bias $\mathrm{Vt}=-1 \mathrm{~V}$, the activation energy for signal B has changed to $\mathrm{E}_{\mathrm{c}} 0.6 \mathrm{eV}$. For the case of the $0.5 \mathrm{eV}$ signal, the deduced activation energy does not show any noticeable change with respect to the bias voltage. The reverse bias dependent activation energy of the of the broad peak B indicate that the broad peak B should be related to continuous band-fike states, which was expected of the nodel involving a defect cluster consisting of dangling bonds, which introduce the continuous band-like slates in the band gap of SiC [1, 12$]$.

From higure 1 , if can be seen that the intensity of signat B was significantly reduced and its shape was also modified white the sample anneals up to $500{ }^{\circ} \mathrm{C}$. We have also investigated the pulse filling width dependence of his broad signal for the $500^{\circ} \mathrm{C}$ annealed sample. It was found that the intensities of these two peaks in the $500^{\circ} \mathrm{C}$ annealed sample do not depend on the filling pulse widh with tp $100 \mu$. Moreover he activation energies of these two peaks were found to be $\mathrm{E}_{\mathrm{c}} 0.60 .7 \mathrm{eV}$, which are close to those of the well-known $Z_{1} / Z_{2}$. This annealing behavion is also similar to that of the deep level $Z / Z_{2}$. We thus suggest that the peaks observed at $\mathrm{T}=300-350 \mathrm{~K}$ in the DUTS spectra of samples annealed at $500^{\circ} \mathrm{C}$ or above be the $Z / Z_{2}$ deep levels. This implies that the dislocation related defect contained in the broad signal has already been annealed out at $500^{\circ} \mathrm{C}$. As seen from the DLTS spectum of the as-implanted sample in figure I, it has already been pointed out that the broad signal should consist of more than one signal and the nitensity dependenees of these signals have different filing pulse width dependence. We thas conclude that the $Z_{1} Z_{2}$ also exists in the as-implanted sample although it is difficult to unambiguously decompose the signals of the broad peak in the as-implanted sample spectrum.

Another pair of deep level defects $\mathrm{E}_{\mathrm{H}} \mathrm{B}_{2}$ (with activation energtes of $\mathrm{E}_{\mathrm{C}} 0.310 .4 \mathrm{eV}$ ) vere clearly observed after the $500^{\circ} \mathrm{C}$ annealing although they were not present in the as-mplanted sample spectum. Thennal annealing studies showed that these two peaks were stil detected after the $1100 \mathrm{C}$ annealng.

\section{CONCLUSION}

Low dose He-impiantation induced deep level defects in n-6H-SiC were investigated. Dislocation related defect was observed in the as-implanted sample. In the DLTS spectra, this dislocation-like defect overlaps with the $\mathrm{Z} / \mathrm{Z}$ deep levels. The dislocation-like defects anneal at $500^{\circ} \mathrm{C}, \mathrm{E}_{1} / \mathrm{E}_{2}$ defects were not detected in the as-mplanted sample, but they are clearly observed after the $500^{\circ} \mathrm{C}$ annealing. Deep level at $0.500 .53 \mathrm{eV}$ (possibly Ef or RDS) below the conduction band was observed in the as-mplanted sample. $\mathrm{E}_{1} / \mathrm{E}_{2}$ and the defect at $\mathrm{E} C 0.53 \mathrm{eV}$ persist after the $1100^{\circ} \mathrm{C}$ annealing. 


\section{ACWNOWUWDGWNWNTS}

The work deschbed in this paper is suported by the grants from the Research Grant Councl of the Hong Kong Special Adminismathe Region, Chma (under project Nos. HKU708501P HKU7 $0302 \mathrm{P}$ and HKU 034OSP and the CRCG HKU.

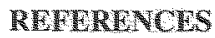

1. H. Morkog, S. Srite, G B. Ga, M. E Lin, B. Sverdov, and M. Bums, J. App Phy, 76. $1362(1994)$.

2. G. Pensl and W. J. Choyke, Physch B 185, 264 (1993).

3. T. Dalbor, G. Pens, H. Masumam, T, Kimoto, W. I. Choyke, A Schoener and N. Nordel, Phys Stat. Sol (a) 162, 199 (1997).

4. M. O.Abodfotohand I. D. Doyle, Phys. Rev. B $59,10823(1999)$

5. A. A, Lebedev, A. I. Veinger D, V. Davydov, V. V. Kozlowki, N. S. Sakina, and A. M. Strelchul, J App. PH. 88,6265 (2000).

6. Th Fank, G Pens, Song Ba, R P. Devaty and W. I. Choyke, Mat Sc. For 338-342, $753(2000)$

7. C. G. Wewmingson, N. T. Son, O Kordina, E. Janzen, and I. L. Lindstrom, J. Appl. Phys. 84, 704 (1998).

8. M. Gong, S. Fung, C.D. Beling, and Z You, J.Appl Phys.85, 7604 (1999).

9. Meidner, T. Frank, G Pensl, A, Kawaswso, H. Itoh, and R. Kranse-Rehberg, Physica $B$ $308.310 ; 633(2001)$

10. X D Chen, S. Fung C.C Ling, C. D Beling, and M. Gong, J. Appl Phys. 94, 3004 (2003):

11. T. Wosinski, A. Apl. Phys. $65,1566(1989)$.

12. P. Oming, E. R. Weber, L. Montelus, H. Alexander, and J. Michel, Phys. Rev. B 32,657 $(1985)$ 